\title{
Entre o diálogo e a
}

dialética: a dimensão

metaficcional do

\section{romance neo-realista}

Ana Paula Ferreira

A book is not an isolated entity:

it is a relationship, an axis of inumerable relationships. ${ }^{1}$ 
Desde que Roland B arthes passou o testamento ao R ealismo, considerando-o um "modo" literário conivente com formas de pensamento totalitaristas, tem-se registado a crescente valorização crítica de "textos" (por oposição a "obras") tendentes à especularidade linguístico-formal bem como à disseminação de sentidos. ${ }^{1}$ Seja resultado de uma desilusão com o curso da História, ou parte integrante da atitude "falibilista" que, segundo R obert Scholes, se tem imposto sobre o positivismo oitocentista, a auto-reflexão característica do romance contemporâneo é dada como sintoma de que o realismo tradicional se encontra esgotado. E mbora concordando que o fenômeno não implica a negação da realidade, nem, mesmo, da função mimética, a crítica converge em distinguir de maneira categórica entre a reportagem inerente a obras realistas e a abstração estética e/ou filosófica que distingue a metaficção. ${ }^{2}$ Daí que se privilegie o que R obert Spyers considera, adaptando uma metáfora de F redric J ameson, como "a cárcere da ficção" ( $p .16),{ }^{3}$ sem atender ao fato de que nem o mais lúdico ou hermético

1. Utilizo aqui Roland Barthes como um entre outros possíveis marcos críticos associados ao descrédito de formas artísticas e de ideologias ligadas à razão iluminista, sensivelmente ao longo do período que assiste à emergência do pós-estruturalismo. Vejam-se do Autor, por exemplo, Le Degrée zero de l'écriture (1953), Writing Degree Zero (1968), espec. pp. 67-73 e "Del' oeuvre au texte" (1970).

2. Além da obra de R obert Alter citada anteriormente, Partial Magic, vejam-se também, R obert Scholes, Fabulation and Metafiction (1979); Patricia Waugh, Metafiction: The Theory and Practice of Self-Conscious Fiction (1984); e Robert Spyers, Beyond the Metafictional Mode: Directions in the Modern Spanish Novel (1984).

3. A frase "the prison-house of fiction" é obviamente inspirada na crítica do estruturalismo e do formalismo russo levada a cabo por F redric J ameson em The Prison-House of Language (1972). 
experimentalismo se fuga a abrir uma janela para o mundo, nem tão pouco a suposta transparência do documento realista pode deixar de reverter à própria linguagem que assim a constrói.

Não por acaso surgidos ao longo das duas décadas que assistem à agonia da palavra de ordem do realismo socialista, os apologistas da metaficção situam-se de modo implícito ou explícito contra o realismo de inspiração marxista que desponta nos anos trinta em várias literaturas do Ocidente numa tentativa de intervir no curso da História. Paradoxalmente, esse novo ou "neo" realismo, ${ }^{4}$ herdeiro direto de concepções e práticas de ruptura modernista, exibe uma autoreflexividade textual que tematiza a própria literariedade com o fim de re-interpretar modelos oitocentistas. Reduzir tal realismo a um certo conceito de "ideologia" para, contra esse fantasma, iluminar a complexidade de textos supostamente isentos de agendas ideológicas contribui não só para o desprezo crítico de formas realistas em geral, mas também para que se ignore até que ponto estratégias ligadas à metaficção podem ser instrumentais para sugerir uma realidade social em vias de transformação.

Se se observa, por exemplo, até que ponto o romance brasileiro do Nordeste e o romance neo-realista português chamam a atenção para os seus processos de representação, seja em confronto com o regionalismo e o realismo social de corte romântico, seja com a "fatia de vida" naturalista, torna-se evidente que a articulação de uma poética é parte integrante do processo de captação da dinâmica histórica. Ao assumir intertextualmente e dessa maneira dialogar com formas narrativas equivalentes a id eologemas do passado histórico que assimila e reinveste, o novo realismo assume, assim, uma dimensão metaficcional que põe em cheque qualquer divisão simplicista, para não dizer fetichizante, entre "obra" (fechada) e "texto" (aberto), entre ideologia e reflexão estético-filosófica.

É uma vontade de estilo ou postura experimentalista o que leva escritores como J orge A mado e J osé Lins do R ego, no Brasil e, posteriormente, Alves R edol, em Portugal, a pôr em cena a memória textual das suas escritas numa tentativa de trazer à superfície a pluridade de linguagens do romance e assim forjar o que vem a ser a densidade histórica do novo realismo5. Podem-se distinguir três aproximações fundamentais a esse processo. A primeira, manifestada em Cacau (1933), de J orge Amado e, depois, em Gaibéus ( 1939), de Alves R edol, caracteriza-se por

4. Utilizo ao longo do presente estudo as frases "novo realismo" e "neo-realismo" como sinónimos, não obstante reconhecer que esta comporta ressonâncias nacionais específicas e lastros de debates críticos não abrangidos pela primeira.

5. Baseio-me aqui especialmente nas ideias desenvolvidas por J ulia K risteva a respeito do "dialogismo" bakhtiniano. Veja-se “Work, Dialogue, and Novel," in Desire in Language, (1990, p. 64-91). O meu estudo Alves Redol e o NeoRealismo Português (1992) representa uma tentativa sistemática de re-interpretar o Neo-Realismo a partir dessa perspetiva. 
uma equívoca recusa não só do gênero romanesco como também da literatura em $\mathrm{si}^{6}$. E mbora a fortuna crítica desses romances tenha vindo a apoiar a sua suposta, aliás aparentemente expressa, falta de intencionalidade artística, importa verificar até que ponto Cacau e Gaibéus Iançam as bases de uma nova "literariedade" estético-ideológica. Suor (1934), de J orge A mado, se bem que já antes, Menino de engenho ( 1932), ${ }^{7}$ de J osé L ins do R ego, fazem patente como tal orientação se forja a partir do encontro, conscientemente assumido a nível intertextual, entre fontes da tradição oral-popular e fontes da tradição literária. A inclusão de referências à arte pitórica em Terras do sem fim (1946), de J orge A mado, e em A barca dos sete lemes (1958), de Alves Redol, desenvolve a dimensão auto-reflexiva do novo romance realista, apontando para a sua filiação numa ampla genealogia artística que abrange perspetivas e estilos tão distantes no tempo e no espaço como em lealdades políticas ou crenças espirituais ${ }^{8}$.

Três momentos de abstração metaficcional pautam, no romance-manifesto de J orge Amado, Cacau, uma visível progressão entre o aberto desprezo pelas convenções literárias à adopção do topus, tipicamente literário, da modéstia artística. A intervenção inicial do narrador establece o contraste básico entre o presente relato, que se quer imediato, e aqueles que, distantes da realidade humana da roça, tendem a embelezá-la com o uso de lugares-comuns tais como "horrorosa tragédia" ( p. 215). Opondo o valor documental da sua narrativa, baseada em testemunhos de trabalhadores e prostitutas, às construções fictícias de escritores burgueses, a instância autoral afirma, assim, e não sem certo orgulho, a sua falta de ambição estética: "P rocurei apenas contar a vida dos trabalhadores..." ( $p$. 266). Essa mesma atitude de (mascarada) indiferença perante as expetativas da instituição literária faz-se representar, uma vez mais, com relação aos materiais de base que entram na composição do romance:

.... Li uns romances antes de começar Cacau e bem vejo que este não se parece nada com eles. Vai assim mesmo. Quis contar apenas a vida da roça. Por vezes tive ímpetos de fazer panfleto e poema. Talvez nem romance tenha saído (p. 271).

6. Utilizo as edições de Cacau e de Suor incluídas em J orge Amado, O País do Carnaval, Cacau, Suor (L isboa: E dições Livros do Brasil, s.d.), pp. 133-145 e pp. 253-388, respetivamente; António de Alves Redol, Gaibéus, 15ạ ed. (Lisboa: Publicações E uropa-América, 1979). Subsequentes referências serão indicadas em forma parentética.

7. J osé Lins do R ego, Menino de engenho, 30aed. (Rio de J aneiro: Livraria J osé Olympio E ditora, 1981). Subsequentes referências serão indicadas em forma parentética.

8. J orge Amado, Terras do sem fim, 55a ed. (Rio de J aneiro: Record, 1987); António de Alves Redol, A barca dos sete lemes, 7ạ ed (Lisboa: Publicações Europa-América, 1977). Subsequentes referências serão indicadas em forma parentética. 
Ressalta aqui, como é óbvio, uma sintomática preocupação estético-formal que contrasta com o tom de escárnio anteriormente dirigido contra as convenções romanescas. Por outras palavras, Cacau não só se articula à sombra explícita do "documento" verídico escrito - as cartas de trabalhadores -, mas especificamente à sombra de um género literário canônico, contra o qual se mede. $\mathrm{E}$, em última instância, é com relação ao mesmo, ou seja, como romance ( que não exclui nem o "poema" nem o "panfleto") que o relato exige ser lido.

Do mesmo modo, Alves Redol abre Gaibéus com um aviso que re-atua, e talvez de forma deliberada, a argumentação equívoca que serve de alicerce estético-ideológico ao primeiro romance nordestino de J orge Amado:

Este romance não pretende ficar na literatura como obra de arte. Quer ser, antes de tudo, um documentário humano fixado no Ribatejo. Depois disso, será o que os outros entenderem (p. 53).

A insegurança que leva ambos os escritores a explicitar e, a partir daí, fazer a apologia da ruptura literária introduzida pelos seus respetivos romances revela, afinal, uma atitude de reverência para com o critério de valor artístico, em particular para com aquele que define o género romanesco desde meados dos anos trinta. ${ }^{9}$ P retendendo, no fundo, explicitar de antemão "o que os outros entenderem", a associação declarada do novo romance realista com o "panfleto" e o "poema", no caso de J orge A mado, e com o "documentário humano", no caso de R edol, põe o acento na heterogeneidade e não necessária confluência, seja formal, seja ideológica, de discursos que configuram a linguagem do romance enquanto género essencialmente "polifônico". 10

Dois amplos filões textuais, representativos de heranças literárias assimiladas pelo neo-realismo, são evocados nas identificações acima referidas. A ambição documental pretende, sem dúvida, ser a faceta mais significativa, mesmo original, do tipo de romance proposto por J orge Amado e por Alves Redol. A enfâse colocada nas vítimas da injustiça sócio-econômica é indicativa da sobrevivência de uma perspetiva naturalista que, tanto no caso do Brasil como no de Portugal, dificilmente se isenta da tendência ao romantismo social. Daí que tanto um "documentário humano" como um "panfleto" e um "poema" co-existam de maneira indestrinçável como intertextos do romance. $O$ fato de que as passagens autoreflexivas apontadas terminem sob uma nota de aparente desafio à opinião do

9. Talvez o realismo de cunho intervencionista que desponta por esta época se possa, efetivamente, considerar como resposta à problematização do modelo do realismo socialista, imposto na União Soviética a partir de 1934. Note-se que Bakhtin, elabora as suas ideias sobre o dialogismo da linguagem no romance entre 1934 e 1935.

10. Mikhail Bakhtin, "Discourse in the Novel", in The Dialogic Imagination: Four Essays by M. M. Bakhtin, (1981) 
crítico-leitor - o "N em romance será" de Cacau e o "Será o que os outros entenderem" de Gaibéus - sugerem até que ponto ditos intertextos, mais que simples marcos de filiação literária, potencializa a contínua especulação estético-ideológica da qual depende o caráter dialético do novo romance realista.

O utras referências intertextuais reinforçam, levando de fato mais longe, esse pendor auto-refletivo. Localizadas ao nível intradiegêtico, e desse modo ocupando um papel funcional na intriga, elas representam duas orientações básicas de dialogismo: obras literárias, por um lado, e narrativas orais, por outro. As relações propriamente históricas que esses vetores discursivos desvelam configuram uma poética postulada como síntese entre "romance" - no sentido de narrativa essencialmente prospetiva (LOSA, 1988, p. 90) -, visão do mundo materialista e, conforme se verá mais adiante, formas de cultura popular, incluindo o folclore e a religião.

Enquanto que, em Cacau, não se indica qualquer autor ou obra em particular no contexto do ataque à tendência idealizante do regionalismo de cunho burguês, Suor virtualmente abre com a menção de um "livro inútil" (p. 259): O moço louro (1846), de J oaquim Manuel de Macedo. É de assinalar que a leitura do mesmo ocupa uma jovem fixada de forma narcisista no "quadro da primeira comunhão" ( $p$. 258). Suor, que às primeiras vistas se limita a descrever um cenário naturalista, enquadra-se pois no confronto implícito entre "romance urbano" romântico, representad o pela obra de M acedo, a narrativa ou 'romance' da salvação cristã, anunciada no retrato do ritual da primeira comunhão, e o modelo contemporâneo de "romance proletário", que Suor pretenderia emular. Tal malha intertextual é revisitada ao final da obra, como suporte da conversão ideológica de Linda, a antiga leitora de $\mathrm{O}$ moço louro. "Livros esquisitos", tal como um que descreve "a situação da mulher na Rússia”, absorbem agora a jovem (p. 329). Leituras "sérias", portanto, que abrem perspetivas de pensamento e ação muito contrárias quer ao escapismo individualista suscitado pela fantasia do amor romântico (no romance de Macedo), quer ao mito de abnegação e caridade cristãs veículado por práticas e leituras religiosas - tradicionalmente a única forma de cultura disponível às mulheres. Não é de admirar, a esse respeito, que uma das primeiras consequências das novas leituras de Linda é a de não permitir que sua madrinha, Dona R isoleta, envie dinheiro para "a igreja de Nossa Senhora do Brasil" (p. 327): "Nunca mais Linda sonhou com casamentos. N unca mais foi à I greja" (p. 332)..$^{11}$

Mais que simples confrontos oposicionias, porém, os diálogos intertextuais esboçados entre "romance urbano" oitocentista e "romance proletário" dos anos

11. Também no romance de R achel de Queiroz, O Quinze (1930) se verifica o mesmo confronto intertextual entre a “brochura de capa berrante" que Conceição insiste em ler para "aprender, para [se] documentar", em vez de acompanhar sua avó vai à igreja. 
trinta; o suposto "mito" da religião e a suposta "verdade" de leituras informadas pelo cientificismo materialista preenchem em Suor uma função historicizante que explora certas contradições de base. Constituem-se, desse modo, margens de significado a partir das quais se torna possível articular a poética do novo romance realista. Curiosamente, contrário ao sugerido pela transformação de leituras e afazeres da personagem Linda ao longo da intriga de Suor, essa poética não se funda na mera substituição de um nexo de textos, de significados estético-ideológicos, por outro, mas sim na sua contínua remotivação semântica, na sua abertura a novos interesses e contingências interpretativas.

Os diferentes vetores do neo-realismo antes identificados em Cacau e em Gaibéus são, de fato, melhor explicitados à luz das referências intertextuais presentes em Suor. Na medida em que pressupõe a rejeição da realidade social presente e a construção de uma outra, mais justa e perfeita, o romance neo-realista partilha de uma certa visão utópica, filiada ao "livro inútil” de Macedo. Neste sentido será, por certo, um "poema"; mas um "poema” social, que se quer tão informativo como edificante ao sugerir uma via de emancipação para os oprimidos. Se isso dota o romance neo-realista do tom do "panfleto", haverá também que ter em conta que o seu caráter didático, eivado de crença e de paixão, não se distancia de forma notável da marca distintiva dos textos religiosos. Por último, o tipo de conhecimento associado ao tratado propagandístico soviético - lembre-se a leitura "séria" que cristaliza o processo de conversão ideológica de Linda - aponta tanto para a ambição "científica" do romance neo-realista, como para o seu referido estatuto "documental".

Paralelamente ao conjunto de relações intertextuais que configuram a identidade discursiva do gênero em foco apresenta-se uma herança oral, de filiação popular. L onge de ser acessória, mera nota de cor local, a inclusão de lendas, mitos e fragmentos líricos no romance neo-realista preenche uma função ideologizante ao mesmo tempo que contextualizante: ao relacionar o novo realismo com uma virtual 'cultura de massas', põe em cheque a tendência regionalista de priveligiar o detalhe picturesco ou exótico. ${ }^{12}$

Menino de engenho, de J osé Lins do Rego, ilustra bem como diversas fontes orais se conjugam para definir a pretensão popular da ficção de cunho intervencionista surgida nos anos trinta. Deixando de lado, por razões de espaço, a análise de (numerosas) canções populares, importa observar o funcionamento

12. A ressurgência das tradições populares na literatura proletária é defendida, precisamente, como estratégia crítica contra a valorização de elementos exóticos e pitorescos no regionalismo burguês. Veja-se a este respeito, Michel Ragon, Histoire de la littérature proletaire en France (1974, p. 137). Desenvolvo a análise dessa estratégia no meu estudo "Garrett e a 'voz do povo' no romance neo-realista: para a remotivação de uma poética", ( 1990 p. 51-68.) 
de três tipos de narrativas orais referenciadas no texto: o relato autobiográfico do "bom criminoso" J osé Silvino (p. 19); as estórias de Trancoso interpretadas em verso pela profissional itinerante Totonha (p. 49) ; e, finalmente, as crônicas históricas contadas pelo avô do protagonista ( p. 91). Além de particularizar uma genealogia textual, essas narrativas trazem à superfície o que pode ser entendido como a ação simbólica que subsume e organiza "o inconsciente político" do romance neo-realista. (J AMESON, 1982) Tal ação faz-se representar, em cada um dos exemplos apontados, na jornada emblemática de um homem comum, desde vítima alienada e marginal a herói da causa do seu povo. Decalcado sobre essa narrativa simbólica básica, o romance projeta-se, finalmente, na dimensão atemporal e universal do exemplum sem, contudo, deixar de apontar a um momento histórico e a um espaço geo-cultural específicos.

Procurando uma definição teórica a partir da remotivação de uma herança textual heterógenea, o romance neo-realista apresenta ainda uma outra estratégia de auto-reflexão que concretiza a sua radical tendência imagística. A inclusão de referências a obras de arte pictórica alusivas a estilos e conceitos de representação característicos de uma variedade de posicionamentos estético-ideológicos estabelece as coordenadas de uma agenda artística que abraça e transcende cada um dos textos, como cada um dos quadros humanos a que alude. São dignos de atenção a esse respeito os romances Terras do sem fim, de J orge Amado, e A barca dos sete lemes, de Alves R edol - sem dúvida dois pontos de relevo nas obras dos dois autores e nos panoramas respetivos ao novo realismo brasileiro e português.

Duas descrições de uma cena pastoril anônima surgem como contrapontos da violência extrema em que o velho fazendeiro B adaró se vê imerso como um dos pretendentes das "terras do sem fim". O personagem contempla, primeiro, a paz idílica da reprodução ao pressentir que se avizinha uma longa e sangrenta disputa com Horácio ( p. 62). Depois, pouco antes do clímax da contenda, evoca a imagem do seu quadro à medida que Ihe chegam versos soltos de canções dos trabaIhadores (p. 205). Se, ao nível superficial da intriga, a cena oferece um contraste irônico entre o espaço idealizado e convencional do quadro e a realidade concreta tanto dos patrões como dos servos em terras do sertão, essa cena pode também ser entendida como modelo abstrato (i.e. teórico) do próprio romance.

O quadro presentifica em forma simbólica um marco da ação política para que se dirige o novo realismo, ou seja, a de contribuir para a invenção - e o alcance - de uma nova realidade social, por força utópica. O idílio pastoril evocativo de outras tantas representações idealizantes da realidade social aponta, pois, para a única "mensagem" agora possível num neo-realismo já despojado do alarme e do entusiasmo associados ao "panfleto" da década precedente. Será por meio da menção ao referido quadro que J orge Amado demonstra uma consciência mais 
apurada de como levar a cabo o seu projeto literário. ${ }^{13}$ Só enquanto "[ gênero] pastoril disfarçado" - tal como William E mpson sugere - poderá o "romance proletário" (ou o neo-realista), resolver o problema formal derivado da aliança imediata e deliberada entre a política e a arte.

U ma forma ainda mais evidente de associação intertextual entre certa tradição da arte pictórica e a tradição literária em que o novo realismo se pretende filiar encontra-se no romance de Alves Redol, A barca dos sete lemes. É de salientar aqui uma sucessão de referências a três famosos pintores espanhóis, em cujas obras o narrador/autor fictício procura orientação para fazer o retrato do seu objeto artístico - o compatriota, humilde e desorientado, que encontra numa prisão francesa na época da R esistência:

O retrato pintado do pai e outro homem tão diferente, que nunca vi outros mais díspares. A um pintou Velásquez com as tintas do sol, da alegria popular, espontânea e um tanto chocarreira, e também as da resignação vitoriosa do pobre diabo, capaz de acreditar na revolução ou num lobisomen; e ao outro o dramatismo contido de G oya com as cores de Greco, saindo das torturas de uma noite funda e bárbara (p. 79-80).

E vocando o tipo de imagens representativas de cada um desses mestres, essas referências, propositadamente não obedecendo a uma ordem cronológica, são instrumentais para dimensionar a descrição do destino trágico do personagem principal; mas, ao mesmo tempo, para sugerir em que medida o relato do mesmo acaba por proporcionar - ao autor fictício, por um lado; ao protagonista, por outro; e, ainda, ao leitor virtual - uma espécie de "luz", qual aquela que desponta no termo da progressão teleológica implícita na tríade Velásquez-G oya-El G reco.

Figura típica do Português aventureiro dos "sete mares", transformado, porém, no humilde imigrante da época moderna, a vida de Alcides B ago-de-Milho tipifica também o destino de um qualquer trabalhador, desde a alienação provocada pela dependência económica à consciência de si e ao desejo de autodeterminação. Assim, as figuras humildes, aparentemente vazias, da primeira fase de Velásquez encontram um paralelo na representação literária do jovem. Os famosos "monstros da guerra" pintados por Goya refletem, desse mesmo modo, a irracionalidade, a violência, a desorientação experimentadas por Alcides, feito mercenário da Legião Estrangeira por um engajador que lhe prometera "trabalho bem pago e mulheres" ( p. 359). As referência às cores de EI Greco “... saindo das

13. Não será redundante lembrar aqui a declaração que antecede o romance Terras do sem fim:

Constato com uma imensa alegria que uma linha de unidade jamais quebrada liga não só toda a minha obra realizada nesses dez anos como a vida que durante eles vivi: a esperança-mais que esperança, a certeza-de que o dia de amanhã será melhor e mais belo ( $p .13$ ). 
torturas de uma noite funda e bárbara “ (p. 80) oferecem à narrativa (tanto no plano particular como no simbólico) uma dimensão futurante.

Como no caso da cena pastoril no romance de J orge Amado, a mensagem essencialmente religiosa transmitida pelo estilo de EI G reco é re-interpretada de acordo com uma visão do mundo materialista. Essa perspetiva ideológica, a par com a evocação da promessa do paraíso cristão aproximam-se ao nível intertextual do romance, sendo sua radical polarização neutralizada pela narrativa simbólica, atuante ou prospetiva, inerente ao mesmo.

Instâncias diversas e, no entanto, congêneres de reflexão metaficcional, os momentos de atividade intertextual focalizadas no presente estudo traçam uma contínua preocupação com o conceito do fazer artístico neo-realista. Numa primeira etapa, correspondente à "quebra escritural", como diria B akhtin, inaugurada pela emergência, nos anos trinta, de uma nova concepção de romance realista, salienta-se o confronto irônico com a herança do romantismo e do regionalismo oitocentistas. Afirmando o seu valor documental contra a tendência escapista e mistificante das representações da realidade social características de tais correntes, o romance neo-realista articula-se, então, como procura ativa de nomear, de re-atualizar a memória textual dentro de cujos parâmetros (históricos e formais) se enquadra sua poética realista. Essa memória, conforme se teve ocasião de observar, pode ser identificada em dois tipos básicos de intertextos: aqueles que confirmam uma tradição literária ou "burguesa" e aqueles que respondem ao apelo de um novo realismo acessível às massas populares. O fenômeno redunda, evidentemente, na pretensão universalista de uma literatura que dialoga permanentemente com textos, com figuras, enfim, com linguagens tanto do passado como do presente com vistas à re-invenção e à transformação do mundo.

E m vez de uma renúncia da "ideologia" e uma (suposta) conseqüente sofisticação do estilo - como pretenderiam certos críticos e detratores do neo-realismo -, o que se regista entre os inícios e a maturidade artística do gênero em foco é, por conseguinte, uma crescente exploração da pluralidade semântica da palavra do romance como forma de militância possível em tempos de repressão. Um dos resultados mais notáveis dessa estratégia, que compreende o esforço da teorização como parte integrante da própria realização artística, parece ser a progressiva internalização textual da estrutura narrativa alusiva ao movimento dialético da História - "o inconsciente político" (para usar a frase de F redric J ameson) que será o denominador comum do romance neo-realista.

A identificação de um intertexto e a análise de sua relação com o texto central pode, com efeito, pôr de manifesto tanto a densidade histórica como o conceito estético que orienta determinada linguagem artística. Se é certo que essa aproximação crítica, seguindo o argumento de Owen Miller (1985), depende da compe- 
tência e da experiência prévia de um/a leitor/a, ela só se legitima na presença de um vestígio intertextual discernível. São esses retalhos, esses fios de um tecido muito mais amplo, formado pelas narrativas de uma orientação e filiação histórico-literária (e artística) específica, que o romance neo-realista nomeia, exibe e reconfigura na tentativa de teorizar - e de fazer o leitor perceber - uma poética feita ação: eis aqui uma prova de que a metaficção não encerra necessariamente um texto num infinito jogo de espelhos imune a preocupações - e convicções - de ordem política. Seja qual for o cariz "democrático" ou "totalitário" que se Ihe queira atribuir.

Ao establecer de forma consciente e deliberada "um eixo de inúmeras relações" - para retomar a frase de B orges citada em epígrafe -, o novo realismo, aqui exemplificado por obras representativas do romance brasileiro do Nordeste e do neo-realismo português, recusa-se, com efeito, a dar por terminada a tentativa de continua auto-reflexão que Ihe é característica. A brecha que as referidas relações intertextuais fazem patenta na dialética entre identidade e diferença, tradição e ruptura, o residual e o emergente ${ }^{14}$ cristaliza uma visão do romance e, por conseguinte, da História como radical incompletude: expressão do movimento, da procura, que implica não só a atividade da escrita e a realidade humana que ela configura, mas também as escritas, as representações, as realidades daqueles que no romance neo-realista continuam a encontrar um eco especular, fragmentos de um passado e um esboço de possível futuro.

14. Por "residual" e "emergente", entendo, respetivamente, os textos assumidos intertextualmente e o texto que se procura afirmar como novo, isto é, o próprio romance neo-realista. Veja-se ao respeito, Raymond Williams, Marxism and Literature [1977] (Oxford: Oxford University Press, 1978), pp. 121-127. 


\section{R eferências bibliográficas}

ALTER, Robert. Partial magic: The novel as self-conscious genne. Berkeley: University of California Press, 1975.

AMADO, J orge. O país do Carnaval, Cacau, Suor. Lisboa: Livros do Brasil, s/d. . Terras do sem fim. 55 ed. Rio de J aneiro: Record, 1987.

BAKHTIN, Mikhail. Discourse in the novel. In HOLQUIST, Michael (ed.). The dialogic imagination: four essays by M. M. Bakhtin. Trad. Caryl Emerson e M ichael Houquist. Sustin: University of Texas Press, 1991.

BARTHES, R oland. Writing Dregree zero. Trad. Annette Laver e Colin Smith. Nova I orque: $\mathrm{Hill}$ and Hong, 1968.

. From work to text. In Image-Music-Text. Trad. Stephen Heath. Nova Iorque: The Noon day Press, 1977, p. 155-164.

EMPSON, William. Proletariam literature. In Some versions of pastoral. Norfolk: J ames Laughlin. S/d.

FERREIRA, Ana Paula. Alves Redol e o neo-realismo português. Lisboa: Editorial Caminho, 1992

. Garrett e a "voz do povo" no romance neo-realista: para a remotivação de uma poética. In Atlântida. Vol. XXXV, 1990, p. 51-68.

J AMESON, Fredric. The political unsconsci ous: narrative as a socially si mbolic act. I thaca: Cornell University Press, 1982.

. The Prison - House of language. Princeton: Princenton University Press, 1972.

KRISTEVA, J ulia. Work, dialogue and novel. In Desire in language. Thomas Core, Alice J arine e Leon S. Roudiez. Nova I orque: Columbia University Press, 1980, p. 64-91.

LOSA, M argarida. From neo-Reali st novel to working-class roman. Dissertação. N ova I orque: New York University, 1988.

MILLER, O wen. Intertextual identy. In VALDÉS, Mario \& MILLER, O wen (eds.). I dentity of literary text. Toronto: University of Toronto Press, 1985, p. 19-40.

QUEIROZ, Rachel de. O quinze. 29 ed. Rio de J aneiro: J osé Olympio, 1982.

RAGON, Michel. Histoire de la littérature proletaire en France. Paris: Albin Michel, 1974 REDOL, Antonio de Alves. Gaibéus. 15 ed. Lisboa: Publicações Europa. América, 1979 . A barca dos sete lemes. 7 ed. Lisboa: Publicações E uropa América, 1977

REGO, J osé Lins do. Menino de engenho. 30 ed. Rio de J aneiro: J osé Olympio, 1981

SCHOLES, Robert. Fabulation and Metafiction. Urbana: University of Illinois Press, 1979

SPYERS, Robert. Beyond the metafiction mode: direction in the modern Spanish novel. Lexington: Kentucky University Press, 1984

WAUGH, Patrícia. Metafiction: The theory and practice of self-conscious fiction. Londres: Methuen, 1984

WILLIAMS, Raynond. Marxism and literature. Oxford: Oxford University Press, 1978. 